\title{
Productive Dissonance:
}

\section{A Musical-analytical Exploration of Teacher Educator Perceptions in a Multicultural Education Program}

\author{
Lynn Violet Clark \\ University of Louisiana
}

U. S. A.

The purpose of this study is to explore, using a musical metaphor, the consonance, counterpoint, dissonance, and resonance of a large-scale multicultural teacher education program. In particular, it examines the different instructional approaches of seven graduate students and two faculty who currently teach an undergraduate multicultural education course at a large midwestern university. By combining a theoretical framework (Bennett, 2010) with a musical-analytical approach, the study explores how the interplay of individual voices contributes to a "productive dissonance" that has the potential to transform the overall program.

Multicultural Teacher Education Programs

Method

Areas of Consonance, Counterpoint, Dissonance, and Resonance

Productive Dissonance

References

Dissonance is an essential element in almost any musical work; it is present when two notes that do not seem to fit together push toward a resolution. While "dissonance" comes out of a Western musical tradition and what is labeled "dissonant" varies depending on cultural context, the idea of using conflicting notes to develop a musical idea is a universal construct. Although dissonance can be destructive, turning music into noise, it is more often productive, resulting in a tension that moves the music forward. The purpose of this study is to explore, using a musical metaphor, some of the tensions inherent in a large-scale multicultural teacher education program. In particular it examines how the needs of the program to create a cohesive curriculum and the needs of the instructors to develop an individual approach may generate a "productive dissonance" that has the power to transform the program. 


\section{Multicultural Teacher Education Programs}

By its very nature, a multicultural teacher education program must embrace multiple perspectives and discourses (Gay, 2010). Drawing on the collective research in the field, Christine Bennett (2010) outlines four broad principles of multicultural education that should be addressed with all pre-service teachers: a theory of cultural pluralism; ideals of social justice; affirmations of culture; and visions of educational equity and excellence. James Banks (1994) posits that multicultural teacher education should illuminate how cultural assumptions and biases shape the way in which we process information. Geneva Gay (2000) explains that we must move beyond cultural categories to see the interrelationship between cultures while maintaining a critical perspective to "deconstruct and reconstruct common ethnic and gender typecasting" (p. 143). Christine Sleeter (2004) argues that the "ideals of social justice" are not enough; multicultural teacher education should help students "name and actively challenge forms of injustice, not just recognize and celebrate differences" ( $p$. 123). Gloria Ladson-Billings (1991) reminds us that pre-service teachers must develop a willingness to explore and discuss their own feelings about the issues and attitudes related to multicultural education. What emerges is a multicultural teacher education program that includes a nuanced approach to cultural and cognitive pluralism, a complex and critical perspective, powerful strategies for reflection and dialogue, and an insistent call to action.

Although stand-alone multicultural education classes are an essential element of most teacher education programs, there is little evidence that these classes can fundamentally change the attitudes and beliefs of mainstream preservice teachers (Cochran-Smith, 2003; Gay \& Howard, 2000; Larkin \& Sleeter, 1995). Advocates of multicultural teacher education often criticize stand-alone classes because they believe an isolated course "trivializes and marginalizes multicultural education and does little to prepare beginning teachers to move beyond traditional approaches to teaching culturally diverse students" (Larkin \& Sleeter, 1995, p. ix). Current trends in teacher education show an increase in an infused approach to multicultural teacher education that replaces distinct courses dedicated to diversity with multicultural experiences or themes woven throughout all teacher education coursework (Irvine, 2003; Potts et al., 2008).

Geneva Gay (1997) calls for an integrated approach to multicultural teacher education that combines the two approaches for "a dual presence in the program offerings" (p.160). She suggests that themes of cultural and ethnic diversity be included in all foundational courses as well as providing distinct courses in the theory and practice of multicultural education. She argues that multicultural teacher education has become a political issue and asks, "If knowledge and diversity is not an integral part of a professional preparation program, how and when are teachers supposed to learn the knowledge and skills they need to teach diverse students?" To Gay (2005), the implications are clear: 
"The ones who are least valued can be easily overlooked without the reformers seeing any contradictions in their visions and action proposals" (p. 223).

To help frame curricular reform, Christine Bennett (2010) suggests six goals of comprehensive multicultural curriculum (see Figure 1).

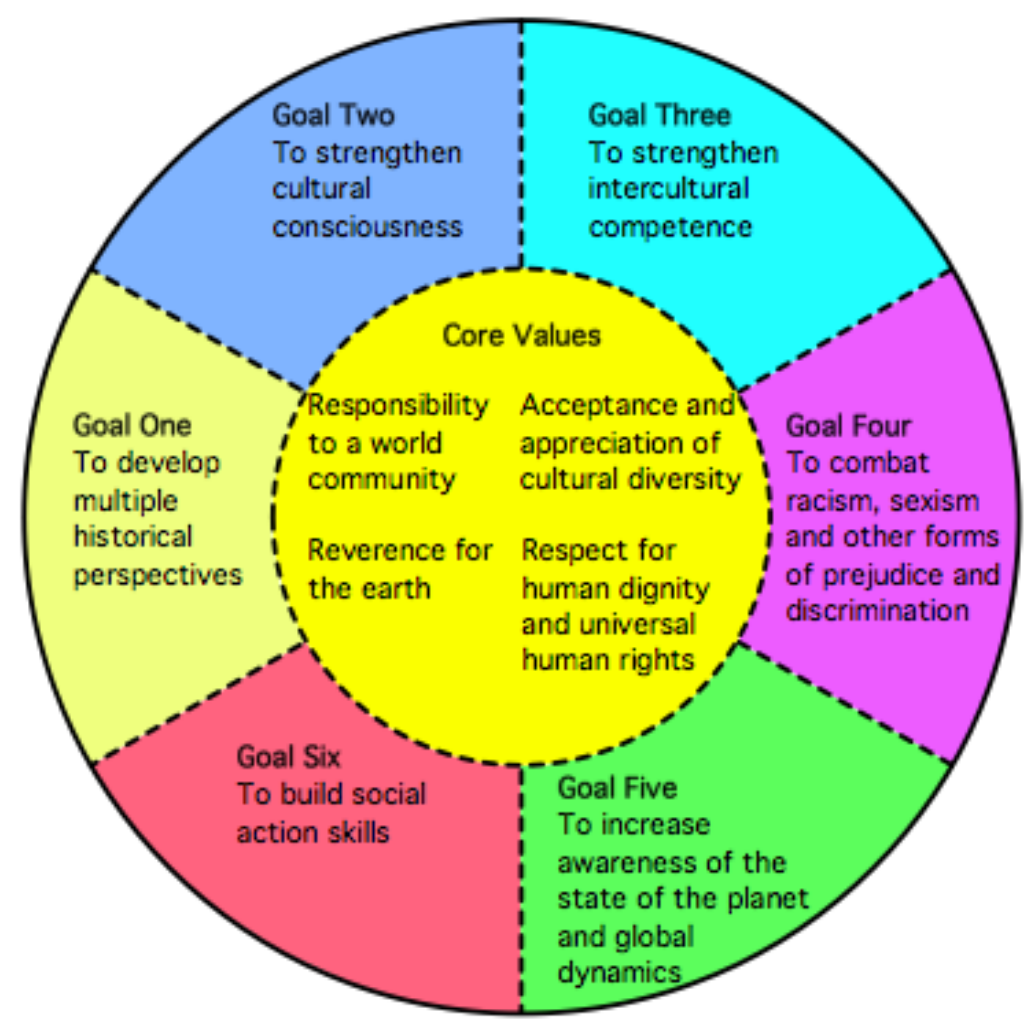

Figure 1: Conceptual Model of Comprehensive Multicultural Curriculum (Bennett, 2010, p. 31)

These six goals are interrelated and draw on the following core values of multicultural education: a responsibility to the world community, respect for the earth, acceptance and appreciation of cultural diversity, respect for human dignity and universal human rights. In addition, the goals and values work on different levels. Whereas the six curricular goals might be more explicit in the curriculum, present in the organization and content of the course, the values would more often be implicit in the approach of the instructor and the structure of the class. Finally, these goals are a framework, not a mandate, for curricular reform. The model does not suggest that each goal carry the same weight but that the goals serve as a guide for course development. Bennett suggests that "ideally teams of teachers within a school...college or university would collaborate on the sequencing and articulation of multicultural perspectives in curriculum objectives, strategies, and materials" (Bennett, 2010, p. 34). 


\section{Method}

This study examines a multicultural teacher education program in a large Midwestern university, which follows the hybrid model suggested by Geneva Gay and was originally designed using the six goals of Bennett (2010). Currently, the program weaves the themes of cultural and ethnic diversity through all methods classes as well as provides a mandatory stand-alone course for all undergraduate pre-service teachers during their sophomore or junior year. Nine sections of the course are offered at both the elementary and secondary levels each semester. Two faculty and seven graduate students teach different sections of the 3-unit course. The faculty and graduate students also participate in a biweekly seminar that provides pedagogical and theoretical support. Although all graduate students participate in a lengthy interview and screening process by faculty and peers, once selected to teach the course, they are given complete autonomy. The result is a diverse and personal approach to course content and classroom strategies. The purpose of this study is to explore that diversity in approach through interviews and analysis of course syllabi to uncover the unique "melody" of each faculty member and graduate student (hereafter referred to jointly as instructors) and how it relates to current research. The data were also analyzed collectively to determine the consonance, or harmony, within the program; the counterpoint, or contrast, of distinct but compatible approaches; the dissonance of conflicting approaches; and the resonance, or reverberation, of certain approaches to shift the tone and structure of the program as a whole.

\section{Data Collection}

In an effort to explore the unique approach, or melody, of each instructor, I developed an interview protocol with lead and follow-up questions based on my three research questions:

1. What curricular and instructional approaches to multicultural education are instructors currently using?

2. How do these different approaches relate to current research in the field of multicultural education?

3. How do these approaches relate to the cultural perspectives and teaching experiences of the instructors?

I conducted face-to-face interviews with all instructors teaching the elementary and the secondary multicultural education courses $(\mathrm{N}=9)$. First, I interviewed the seven graduate students (4 male and 3 female). All seven graduate students were doctoral candidates; two of them were international students from Hong Kong and Korea respectively and one self-identified as Latino. I interviewed the two faculty members (female) who self-identified as 
White and American Indian. In addition to teaching course sections, the faculty members also co-directed the bi-weekly seminar that supported the graduate students. I received syllabi from all nine instructors for content analysis.

Interviews were tape-recorded, took place in an informal setting, and ranged from 30 minutes to one hour. I used a semi-structured protocol that allowed participants to direct the interview, and I used the course syllabi as a prompt for dialogue.

\section{Data Analysis}

Transcribed Interviews were sent to participants for member check, and in some cases, they were returned with clarifications. The approved transcriptions were entered into qualitative software for analysis (Hyperresearch). These data were then analyzed using both a priori and emergent coding schemes at the descriptive, interpretive, and pattern level (Miles \& Huberman,1994). A priori codes reflected the current research in multicultural education, in particular the conceptual framework of Christine Bennett (2010), while the emergent codes arose from those themes that resonated with multiple participants. In addition, I examined instructors' descriptions of students' receptiveness and resistance to the content and how these perceived reactions might relate to the instructional approach and power relations. I triangulated my analysis of individual interview data with a similar analysis of each instructor's course syllabus. Working with a second reader, I refined my coding scheme at the pattern level (Lincoln \& Guba,1985).

Because the context of the interview was one of lengthy talk, I also used an arts-based research approach that examined the structure as well as the tone of the talk (Carspecken, 1996). I used a musical-analytical approach because music provides another "language" with which to describe, interpret, and ultimately understand different approaches to teaching and curriculum (Barone \& Eisner, 1997). In an effort to perceive the combined music of the program, I examined the data collectively as if the participants were discrete musical passages within a shared composition. In particular, I documented instances of counterpoint (harmonizing but discrete melodies), consonance (groups of harmonious tones in a chord), and dissonance (lack of harmony that seeks to be resolved) between and within participant interviews. Finally, I looked for areas of resonance (complimentary tunings: all strings vibrate when only one of the strings is struck) that were program wide.

\section{Areas of Consonance, Counterpoint, Dissonance, and Resonance}

As noted earlier, I used the Bennett's (2010) Six Goals of Multicultural Curriculum as an analytical frame (see Figure 1). Although every instructor 
addressed all six goals in one way or another, the time, importance, duration, and dynamic placed on each goal were different for each instructor. What emerged were themes related to each goal that were emphasized by all instructors (consonance), themes that were unique to each instructor but supported a cohesive philosophy or theory (counterpoint), and themes that seemed to be in conflict with each other (dissonance). Finally, the analytical frame provided a referent to track those trends that suggested future areas of growth within the program (resonance).

\section{Consonance}

Consonance is when two or more musical notes sound good together; it is considered the opposite of dissonance. As noted earlier, musical ideas like consonance and dissonance differ according to culture, but in general, consonance is when a chord, interval, or harmony seems stable and free from musical tension. For example, there is common agreement amongst instructors that the course is merely one step in a succession of steps that begin before the class period and will continue beyond these "four walls." All instructors felt that the course serves as a prompt to activate modes of understanding, confront assumptions and misconceptions and "wake up" the students to the cultural and socio-political forces that shape their existence.

There was also universal agreement that the nature of the predominantly Midwestern student population was a strong determinant in course organization and focus: "If we taught somewhere else, we would construct our course very differently." The instructors see their students as homogeneous, middle to upper middle class, White, and traditional with a limited perspective: "So many of the students come from small towns, where there is not a lot of diversity that they see-everyone looked like me and went to the same church." Additionally, instructors felt that the students were generally blind to issues of privilege and power: "They don't recognize the privilege of where they are-for the most part they are white middle class students." Furthermore, instructors felt that the classes provided few direct experiences of diversity because of the homogeneity of the student population: "I have taught 100 students-four black students, and two openly gay and about ten Jewish students-other than that [the class] is white, middle class or higher, predominantly Christian, and heterosexual."

This cultural homogeneity is also tied to the primary misconception of most students - this class is not about them. One instructor summed up the experiences and frustrations of the group: "On the first day of class, I have them write a paragraph about their culture. The white kids can't do it: 'I guess I am kind of a mutt.' They will define 'culture' as ethnic roots, but they can't make the connection between family, language, and living. They think that they don't have a culture." 
Several instructors also noted that their students felt the class was redundant ("I have already had a class in diversity - like you can have a class and you are done") or inconsequential ("I am going back to my small little town and there is one black family, so I don't have to worry about it"). One instructor noted the students also had misconceptions about the course approach: "They think that it is all going to be self-reflections, that if they just talk about their feelings they will be fine." A few instructors also mentioned that students had misconceptions about meritocracy and the "protestant work ethic" as just constructs.

Instructors were given a lot of autonomy in course design and were encouraged to draw on their unique cultural perspectives. "We have a lot of flexibility to design the course," noted one instructor, "I bring a lot of my own strengths." All instructors used broad definitions of culture that went beyond race and ethnicity to include sexuality, socio-economic status, gender, exceptionalities, language, and religion. All focused on the interactions between those categories and how they related to current and historical issues. The themes of power and privilege run through every course syllabus, as do the related themes of normality and diversity.

In addition, there seems to be a concerted effort to use an inquiry approach to learning: "...although the course is about the body of work of authors, there is an attempt to teach depth of inquiry as teachers-not just content and strategies." This emphasis on "teachers as researchers and intellectuals" was present in all but one of the interviews, and then it was a conscious omission: "In the class we don't do the theory; theory doesn't apply. I remember being an undergraduate; I could care less about theory."

Another area of consonance is the focus on dialogue. In several cases, course assignments centered on students' development of dialogic skills. Whether the dialogue took place in person or online, there was a focus on informed speech that went beyond opinion: "...people don't talk about these issues. They want to talk, but the discussion is uninformed. They talk about their feelings, but they don't have a lot of information." In some courses there was more of an emphasis on the development of discussion strategies and studentto-student interactions, with references to how these would prepare students for future interactions with colleagues and the community, while in other courses there seemed to be more emphasis on the development of the individual voice and inner dialogue. However, all instructors recognized that dialogue should work on two levels-an inner dialogue and an outer dialogue. "They must have dual consciousness; they must always have two levels. They have to make sense of "that" [gesture out there] and "this" [gesture into self]," noted one instructor. "At the end of the course I say, "We learned about a whole lot of other people, but the person you have really learned about it you." Whereas these areas of consonance created a rich harmonic structure that served as a framework for the program, there also seemed to be independent melodies that moved within that harmonic frame. 


\section{Counterpoint}

Counterpoint is when there are simultaneous melodic lines in a piece of music. These melodic lines work within a common harmonic structure, but they rise and fall independently_each creating a unique melody. For example, instructors organized their courses in distinct ways. Several of the instructors took a conceptual approach, constructing their courses around the idea of pluralism as a democratic mandate and how that related to different issues and themes within multicultural education. Other instructors divided their syllabi into cultural categories and focused on the complexity within and interaction between these categories. Still other instructors immersed their students in real-world examples and experiences. These same instructors also organized their class by cultural category but then critically examined these categories through case study examples and direct experiences in an effort to confront students with the issues related to each cultural category.

In an effort to deepen the dialogue, instructors took different approaches to diffuse traditional teacher/student power relations. Whereas some teachers systematically removed themselves from the dialogue through a series of guest speakers, others remained in the conversation but created a safe space for dialogue where the students would not just "tell me what I want to hear." Instructors drew on their own cultural "funds" to shape the power dynamic in their classroom. Some instructors shared their perspectives as a prompt for discussion, some presented stereotypical images or materials to engage students, and some said they "sit back and let it happen. I will write down a note to say [something], and it will get said [by a student]." Many tried to make the process transparent: "I am a learner. I may be seen in a position of power, but at the same time I am learning...even though I construct the class."

Instructors also shared their unique cultural identity with their students and used it as a resource to prompt dialogue and inquiry. Several of the instructors have lived overseas or are bi-lingual. Some identified strongly with their gender or sexuality, while others drew on their ethnic backgrounds. In particular, one instructor, who is fair-skinned with red hair and a Hispanic name, uses the common misconceptions about his/her cultural heritage to make students aware of their assumptions:

I am Hispanic but from Galicia [Spain] and it is a heavily Celtic area. So I always have to explain and rationalize. I dealt with all of the assumptions-do I speak Spanish? The first day [of class] I write on the board: What do you think I look like? What language do I speak? We want to put people in unique categories, but people don't always fit in these categories.

Each instructor also focused on developing different aspects of their students' awareness of cultural diversity through related materials and activities. One 
instructor used film to "push them to see the diversity around them." Another instructor focused on classroom dialogue to create a "strong voice," while another tried to engage his/her students in "direct experience." One instructor focused on the inner-dialogue and "social consciousness," while another focused on "teaching in action." Finally, one instructor sought to engage the hearts of his/her students by beginning and ending class with the statement: "...the work we do here is about loving and teaching all children." What emerges from these diverse foci is an image of a human being - made up of an eye, a mouth, a hand, a heart, a mind engaged in reflection, and a body ready for action. This in turn highlights an interesting aspect of counterpoint. Even when notes seem to be moving together as chords (e.g., all lines have the same rhythm) the individual musical lines may still be considered counterpoint. By listening to the inner voices within a chord, one can hear how the rich bass line serves as a countermelody to the expressive soprano line and the alto and tenor are singing a duet.

\section{Dissonance}

In contrast to the first two musical categories, dissonance describes those notes that sound harsh or unpleasant when played at the same time; whereas counterpoint may have contrasting voices within a common harmonic structure, dissonant notes often operate outside that shared structure. Because dissonance is considered unstable, it creates a musical tension that has the power to expand the harmonic structure by pulling the listener toward a resolution that may lie outside of the existing structure. How and when dissonance is used frequently provides insight into a particular musical style or tradition. In the Western musical tradition, dissonance is often used to develop and extend musical themes. In the study, instructor perceptions of student receptiveness to the course content and activities were often dissonant. While there was an overall recognition that "they don't want to read," some instructors seemed more receptive to the limitations of their students ("They are unskilled undergraduate students. I try to be really sensitive about this"), while others felt that they must "protect our teacher-intraining's future students" by using guest speakers and provocative activities to "shock" teacher candidates into awareness.

Moreover, the instructor's perception of students' positive or negative response seemed to be linked to the overall tonality of the interview. In other words, if instructors were positive about their students' ability to grasp the course content and expand their perspective, the interview was generally upbeat, or in a major key, whereas those instructors who were less positive about their students' misconceptions and limitations often spoke in a melancholic or minor key. This is not to say that there were not minor chords within major keys or that "minor" should be viewed pejoratively, rather that these minor moments served to illuminate areas for further exploration. For example, some instructors were discouraged with the state of the multicultural education field in general and a 
shift away from social justice themes in many teacher education programs. Others were frustrated by the demographic and socio-political context of the course (e.g., Midwestern university, politically conservative state, mostly White population) and the lack of diversity in the classroom. Finally, several were upset about the institutional constraints that provided only one course that focused on multicultural issues in the teacher education program.

In one interview that was more minor in mode, the idea that the students perceived the course as having less value than other courses emerged: "There is not another course like this-where you have to rationalize why you teach the course." Although this was not part of the original interview protocol, as the topic was explored in subsequent interviews, it became clear that this was an issue for other instructors: "Students perceive this class as of less value." When asked how s/he dealt with student perceptions, the instructor explained how s/he had students look for teaching jobs, "All of the jobs were located in cities... I said, 'You tell me how this class is not important." Other instructors appealed to the patriotism of their students ("pluralism as a democratic mandate...I use it like a mantra."). These instructors maintain that there is a core of knowledge that is essential to becoming, "active agents in a pluralistic, multicultural society."

Perhaps the most striking dissonance in instructional approach was how instructors addressed power relations in the classroom. Whether they perceived themselves as the primary motivator ("I consider myself progressive and a very animated teacher...I teach very outspoken"), or as the mediator of power ("Ten out of the fifteen classes, I am outside of the classroom...removing myself...giving the power to the person leading the group. I am tired of being in that position."), some instructors sought to maintain traditional student/teacher power relations. At the other end of the continuum were instructors that divested themselves of power by giving it to their students: "I really want to give power to them. I do not want to be a powerful figure in my classroom." This de-centered approach mirrors the approach taken by the course administrator during the biweekly seminar that supports the instructors: "There weren't clear lines between who was a professor and who was a doctoral student...We were each able to contribute to each other's knowledge."

\section{Resonance}

Whereas the first three categories describe the different ways in which notes were interrelated within a musical work, resonance describes the phenomena in which harmonically related strings will vibrate when only one is struck. As noted earlier, the bi-weekly seminar is a chance for the seven instructors and two professors to share their resources and challenges from the classroom. Two of the newer instructors noted that the seminar was a "fund for activities," while the more experienced instructors valued the pedagogical support. What is evident in those interviews that referenced this seminar as a source of support was that it was a safe and rich space in which to "tune" their 
craft: "I think the meetings are more supportive of ourselves than they are necessarily telling us what to do. At the beginning [of the semester] we talked more about pedagogical support (here is a great activity or tip), now it is more support of who we are." A critical component seems to be the modeling of the program advisor: "When she talks about teaching, she describes what she does. She will respond in a certain way. She will show me ways to protect the student." "The "tuning" that takes place during these seminars not only contributes to the individual development of each instructor's melody, but to the collective music of the multicultural education program.

One example of resonance amongst instructors is a growing value placed on an international perspective. Most of the instructors made a point of including an international perspective within their course content and activities or expressed an intention to do so: "In the future I will bring in more international readings." The focus may be due in part to the inclusion of two international graduate students as fellow instructors but also may be a result of the personal philosophy of the course advisor; she values the funds of knowledge that international students bring to undergraduate teacher candidates. One noninternational instructor summed up, and seconded, her philosophy, "I applaud [our advisor's] focus on having international students teach the class. They are not valued; they are marginalized as graduate students. [Our advisor] recognizes that they can bring something to the discussion that WASPS can't." In an effort to promote understanding, the advisor also includes an activity in her syllabus that has students interview an international graduate student over the length of the course. She noted that this activity not only gave international graduate students opportunities to work on their English, but often changed the perspectives of her non-international students: "There are not as many opportunities for students to have empathetic relationship with their instructors; they don't think that if they just work on listening, they will get it. Before when they were in these classes [taught by international students], they felt incensed. Now, they are advocates for the [international Associate Instructors]."

\section{Productive Dissonance}

While it is tempting to focus on the rich contrapuntal composition of the program presented in the findings, it is the areas of dissonance that provide the greatest insight. Using the six goals of multicultural curriculum as a heuristic (see Figure 1), these data suggest that although all six goals are explicit in all nine of the instructors' syllabi and referenced in their interviews, the core values, chief among them "acceptance and appreciation of cultural diversity" and "respect for human dignity," seem to be integrated into the class structure of only some of the instructors. In her article, "Acting on Beliefs in Teacher Education for Cultural Diversity," Geneva Gay (2010) argues that multicultural education programs must affect the underlying value assumptions of both instructors and students. She cites Cuban (1988) in arguing that programs must make second order changes 
to effectively address current multicultural issues. Like Banks' (2005) transformative curriculum, second order changes work at the structural level to impact all dimensions of classroom practice.

For example, while every instructor proclaimed a respect for multiple perspectives (Goal 1) and eschewed the deficit model, some instructors also recognized the core value that their teacher candidates had diverse and valuable cultural perspectives: "I have never met a student that just really didn't want to be a good teacher-didn't care. For the most part my students seem to be really passionate about teaching." As noted earlier, some instructors seemed more receptive to their students' perspectives and consciously created a space for diverse voices in the classroom. Several instructors began their classes with assignments or activities that asked students to explore their cultural identity and how it was shaped by and impacted other cultures (Goal 2: cultural consciousness). In some classrooms instructors deliberately divested themselves of their power so that they could listen for those voices that might be perceived as dissonant (Goal 3: intercultural competence): "It is their classroom...not mine. So I am in there as a colleague and not an instructor. If I give them my power, they give my power back."

Although there was an overt emphasis in each syllabus on recognizing White privilege and combating racism (Goal 4: combat racism), some instructors took care to address their students' resistance to the topic of racism (core value respect for human dignity). When asked to discuss students' misconceptions, instructors' responses echoed the work of Beverly Tatum (1992). Students thought race was a taboo topic ("She thought it would be racist to say that the woman was white"), they thought that the USA was a just society regarding racial issues ("At the beginning of the class a lot of students say that we have no racial problems [in the USA]"), and they denied any personal prejudice ("They believe that they are not racist"). Although some instructors chose to meet these areas of resistance through whole class instruction and teacher-led discussions, others engaged their students individually and privately, probing students' misconceptions through personal email correspondence, extensive comments in papers, and activities that allowed students to construct their own meaning.

As noted earlier, some instructors addressed global issues more than others; however, the inclusion of two international instructors clearly communicates the value placed on an international perspective by the course advisor. Because of their active participation in the bi-weekly seminar, these voices have the potential to resonate beyond the explicit content (Goal 5: Awareness of global dynamics) to produce an internalization of the core value "responsibility to a world community" by those instructors who value the biweekly seminar.

All instructors addressed issues of social justice and the call to social action in their syllabi; however, their instructional approaches lay along a continuum with those that favored a more passive approach at one end ("They don't need to go out and protest, but they need to be informed") and those that favored a more active approach at the other ("I would have them write a letter 
about a diversity issue in school"). While most instructors interviewed would have agreed with Christine Sleeter (2004) that the ideals of social justice are not enough, several instructors felt that "time was a barrier" to meeting this goal (Goal 6: Build Social Action Skills). One instructor suggested that the course have two sessions, one in the classroom and one in the field. Another invited students to continue the conversations begun in class beyond the term: "That is the hard part of this class-there is no way to follow up with the students who want to engage in this level of thinking and teaching. The invitation remains open with me, but not enough come back." Although all instructors recognized the limitations of their stand-alone class, there is the shared expectation that students will be different, if not transformed, at the end of the course: "My fundamental belief is when they get out of this course, ignorance is no longer an excuse."

As noted earlier, dissonance is most pronounced in those core values that relate to diverse student responses to the program content and student/teacher power relations. Because dissonance is in itself relational (e.g., one note can only be dissonant in relation to another note), it is not surprising that it is in the relationships-between students and instructors and students and new ideasthat one perceives the most dissonance in the program. However, it is the response to dissonance that determines whether that dissonance is productive or destructive to the program overall.

To refine the musical metaphor, these findings suggest that it is not the consonance or dissonance of individual voices, but rather the overall musical form, or program structure, which should be examined. In Western musical tradition, dissonance is viewed very differently depending on the time period. In classical musical forms, dissonant notes must be first prepared and then resolved, or begin and end in consonance; however, modern, or $20^{\text {th }}$ century, music has become increasingly accepting of dissonance that is both unprepared and unresolved. These new musical forms allow for dissonance that is both part of and apart from the harmonic structure of the piece. In this way, dissonance ceases to be an either/or binary that is constrained by the consonant sounds, or norms, of the group. Instead, dissonance has the potential to produce a new musical structure, or form that is liberated from the driving need to resolve all differences.

What this means to multicultural education is that dissonance, if it is viewed as productive, can possibly transform a program at the structural level. This has implications for research in student resistance to multicultural education courses (Brown, 2004) and issues of student voice within the classroom (Delpit, 1988; Ladson-Billings, 1991). Furthermore, the bi-weekly seminar, which seems to offer a safe and shared space where dissonance can exist unresolved, has implications for practice in large-scale multicultural education programs. 


\section{References}

Banks, J., \& Banks, C. (2005). Multicultural education: Issues and perspectives. Hoboken, NJ: Wiley Jossey Bass Education.

Banks, J. (1994). An introduction to multicultural education. Needham Heights, MA: Allyn \& Bacon.

Barone, T., \& Eisner, E. W. (1997). Art-based educational research. In R. M. Jaeger (Ed.), Complementary methods for research in education (pp. 7394). Washington, D. C.: American Educational Research Association.

Bennett, C. (2010). Comprehensive multicultural education: Theory and practice (7th ed.). Boston: Allyn and Bacon.

Brown, E. (2004). What precipitates change in cultural diversity awareness during a multicultural course: The message or the method? Journal of Teacher Education, 55(4), 325-340.

Carspecken, P. (1996). Critical ethnography in educational research. New York: Routledge.

Cochran-Smith, M. (2003). The multiple meanings of multicultural teacher education: A conceptual framework. Teacher Education Quarterly, 30(2), 7-26.

Cuban, L. (1998) How schools change reforms: Redefining reform success and failure. Teachers College Record. 99(3), 453-477.

Delpit, L. D. (1988), The silenced dialogue: Power and pedagogy in educating other people's children, Harvard Educational Review, 58(3), 280-298.

Gay, G. (1997). Multicultural infusion in teacher education: Foundations and applications. In A. M. M. K. Kitano (Ed.), Multicultural course transformation in higher education: A broader truth. Boston: Allyn \& Bacon.

Gay, G. (2000). Culturally responsive teaching: Theory, research, and practice. New York: Teachers College Press.

Gay, G. (2005). Politics of multicultural teacher education. Journal of Teacher Education, 56(3), 221-228.

Gay, G. (2010). Acting on beliefs in teacher education for cultural diversity. Journal of Teacher Education, 61(1-2), 143-152.

Gay, G., \& Howard, T. (2000). Multicultural teacher education for the 21st century. Teacher Educator, 36(1), 1-16.

Irvine, J. J. (2003). Educating teachers for diversity: Seeing with a cultural eye. New York: Teachers College Press. 
Ladson-Billings, G. (1991). Preparing teachers for diverse student populations: A critical race theory perspective. Review of Research in Education, 24(1), 211-247.

Larkin, J. S., \& Sleeter C. E. (1995). Developing multicultural teacher education curricula. Albany: State University of New York Press.

Lincoln, Y. S. \& Guba, E. G. (1985) Naturalistic inquiry. Beverly Hills, CA: Sage.

Potts, A., Triplett, C., \& Rose, D. (2008). An infused approach to multicultural education in a pre-service teacher program: perspectives of teacher educators. International Journal of Multicultural Education, 10(1). Retrieved March 5, 2010 from http://ijmejournal.org/index.php/ijme/article/view/39/145

Miles, M. A., \& Huberman A. M. (1994) Qualitative data analysis: An expanded sourcebook. Thousand Oaks, CA: Sage.

Sleeter, C. (2004). Critical multicultural curriculum and the standards movement. English Teaching: Practice and Critique, 3(2) 122-138.

Tatum, B. D. (1992). Talking about race, learning about racism: The application of racial identity development theory in the classroom. Harvard Educational Review, 62(1), 1-24. 